\title{
A narrativa de si em blogs de moda feminina: entre a subjetividade e a alteridade
}

Evandra Grigoletto*

Rita de Kássia Kramer Wanderley**

\section{Resumo}

Neste artigo, a partir de uma perspectiva discursiva, buscamos observar a relação entre subjetividade e alteridade nas narrativas de si em blogs de moda feminina. Entendemos a narrativa virtual de si como os movimentos do sujeito na rede que envolvem a experiência da escrita como testemunho (de si e do outro), sempre associada à materialidade da imagem do corpo. A partir das análises realizadas, observamos que o movimento de subjetivação das blogueiras está determinado pela alteridade e se materializa tanto pela escrita quanto pela imagem do corpo. O relato da experiência inscreve-se discursivamente no espaço virtual por meio de testemunhos, que possibilitam tanto movimentos de identificação quanto de resistência, ambos determinados pelo discurso do capital.

Palavras-chave: Narrativa de si. Blogs de moda feminina. Subjetividade. Alteridade.

\section{O testemunho} ressignificando a existência: palavras iniciais

A escrita, por produzir traços constitutivos de identidade, carrega marcas, revela cicatrizes (d)nos sujeitos que participam dessa experiência. (SCHONS; GRIGOLETTO, 2009, p. 597)

A escolha dessa epígrafe para iniciar este texto revela, como a própria citação destaca, marcas de uma história, de uma experiência acadêmica e de vida que vivi com Carme Regina Schons, a quem dedi-

\footnotetext{
Doutora em Teorias do Texto e do Discurso pela UFRGS (2005). Docente do Programa de Pós-Graduação em Letras da UFPE. E-mail: evandragrigoletto@gmail.com

** Doutoranda do Programa de Pós-Graduação em Letras da UFPE. E-mail: ritinhakramer@gmail.com
}

Data de submissão: mar. 2016 - Data de aceite: maio 2016 http://dx.doi.org/10.5335/rdes.v12i1.5955 
camos o dossiê deste número da revista Desenredo.

Peço licença aos leitores, e também a Rita Kramer, que assina este texto comigo, para iniciar esta reflexão produzindo uma narrativa em primeira pessoa. Sim, uma narrativa, que será tema deste texto. Uma narrativa porque ela se materializa na experiência da escrita. Experiência que já tive a oportunidade de compartilhar com Carme. Demoramos (Rita e eu) a nos decidir sobre o que, de fato, iríamos tratar neste artigo, dentro da temática da subjetividade e da alteridade. Quando decidimos pela abordagem da narrativa de si (e certamente essa escolha passou pelo atravessamento do inconsciente que constitui todo sujeito de linguagem), aquilo que estava esquecido lá na memória, na nossa história de colegas de trabalhos na Universidade de Passo Fundo, entre 2006 e 2008, reverbera em mim e traz à tona textos e outros trabalhos que realizei com a Carme sobre escrita de si. Estranha coincidência?! Não... São os sentidos produzindo laços/ enlaces, significando.

Tais textos vão ser retomados e citados ao longo do artigo, dando voz a essa ausência-presença da Carme entre os analistas de discurso. Em um desses textos, afirmamos que "o testemunho ressignifica o envelhecimento e a sua existência" (SCHONS; GRIGOLETTO, 2009, p. 597). Atualizo aqui esse enunciado, dizendo que o testemunho, neste momento, ressignifica a existência, mas também a ausência, (re)velando cicatrizes, alegrias, angústias que marcaram o meu convívio com essa grande profissional, mulher, amiga que foi Carme Regina Schons. O seu legado pode ser lido nos seus textos e também nas lindas telas que pintava.

Manter esse legado "das ideias, palavras ou pinturas é mantê-la viva entre nós". Essas são palavras registradas na experiência da escrita pela filha da Carme, Karen. Já João, ${ }^{1}$ seu filho, nos presenteia com a seguinte reflexão: “[...] as lições - inconscientes ou não - das pessoas - vivas ou não - transcendem o óbvio, sendo aquilo que move ou não deixa o nosso corpo se mover". Ou seja, suas lições, Carme, ressoam nas palavras dos seus filhos. Sua existência continua produzindo sentidos em todos nós.

E tudo isso nos diz muito sobre o que é a experiência da escrita, o quanto ela revela do sujeito escrevente e o quanto esse sujeito está determinado pelo outro, pela alteridade que necessariamente 0 constitui. Entre as múltiplas experiências de escrita possíveis, elegemos trabalhar neste texto com a narrativa de si materializada em blogs de moda feminina, observando a relação entre subjetividade e alteridade. Essa seleção ocorreu, de nossa parte, por observarmos a importância, nesses blogs, da escrita sobre o corpo e da imagem do corpo como um modo de inscrição do sujeito em determinados discursos. Partindo da perspectiva da análise de discurso pêcheuxtiana, e observando as inscrições dos sujeitos no espaço virtual, entendemos que a materialização da narrativa de si se dá não apenas pela escrita, mas também pelo corpo, já que, se a primeira revela marcas da subjeti- 
vidade do sujeito, o segundo materializa sua própria subjetivação.

Os blogs, considerados como ambientes de narrativas de si situados no espaço virtual $^{2}$ contemporâneo, são duplamente determinados: pela escrita e pela imagem. Os blogs de moda e beleza feminina, especialmente, têm crescido em acessos e importância midiática no espaço virtual e parecem estar ocupando o papel que antes era das revistas de moda e variedades dirigidas ao público feminino. A ascensão de blogueiras de moda e beleza, como Camila Coutinho, do blog Garotas Estúpidas, ${ }^{3}$ elevou o status dessas páginas e também demonstrou o poder de lucro que os blogs de moda poderiam gerar com as divulgações patrocinadas e com os anúncios. Hoje, esses canais funcionam como veículos de comunicação, em que as profissionais blogueiras ocupam a posição de blogueiras-jornalistas-publicitárias, responsáveis por dar dicas de moda, beleza, bem-estar e todos os assuntos relacionados.

A posição de blogueira, ao falar dos assuntos de interesse feminino, passa a ser, nesse lugar virtual, não apenas a de informar e divulgar, mas de dizer de suas próprias experiências com produtos, viagens, serviços, etc. Ou seja, a narrativa de si, da experiência de vida do sujeito-blogueira, funciona como uma das estratégias constitutivas do discurso da blogagem de moda. Não basta falar do produto; o que vale, nas redes, é a experiência da blogueira com o produto. Essa experiência "pessoal” presentifica- -se nos textos e nas imagens - registros de cada segundo da vida das blogueiras - constituindo-se um vasto campo de arquivo digital das narrativas de si atravessadas pelo discurso mercadológico.

No âmbito dos blogs de beleza feminina, assim, prevalecem as narrativas de si, os testemunhos e o registro minucioso dos hábitos e costumes dos sujeitos-blogueiras. Desse modo, pretendemos observar como funciona e como se dá a presença da subjetividade na sua relação com a alteridade no discurso das blogueiras, materializado nas narrativas de si.

\section{O espaço virtual} ressignificando a narrativa de si: a subjetivação pelo discurso no intervalo entre singularidade e alteridade

Pensar a narrativa de si na contemporaneidade impera a marcação do virtual como espaço em que ela se inscreve. Se, antigamente, a experiência da narrativa de si passava pelo registro em diários pessoais, hoje não é mais possível pensar esse registro de si fora da rede. Há disponível nas redes uma série variada de aplicativos e ferramentas virtuais que se propõem a virtualizar em imagens, sons e escritas as vidas "reais" dos sujeitos. Ou melhor: reinventar e recriar a vida desses sujeitos em um espaço outro. E a inscrição nesse lugar aponta-nos para outros modos de materialização da subjetividade, que não se dão mais somente pela escrita, mas 
também, como já afirmamos, pelo corpo materializado na imagem.

A escrita, neste trabalho, não está dissociada nem do sujeito nem do simbólico. "A inscrição do sujeito na letra é um gesto simbólico-histórico que lhe dá unidade, corpo, no corpo social" (ORLANDI, 2006, p. 24). A escrita digital está materializada nas letras que atravessam o caminho dos dedos em direção às telas por meio de pixels; essa escrita digital está atravessada pelos signos do virtual e da Web 2.0: a imagem, o som e o movimento. Esses são elementos do corpo da escrita no virtual, que virtualiza a letra, mas, sobretudo, o corpo, no desejo de virtualizar a vida.

Designaremos aqui, portanto, em um gesto teórico-metodológico, como narrativa virtual de si esse movimento do sujeito na rede que envolve a experiência da escrita como testemunho (de si e do outro), sempre associada à materialidade da imagem do corpo. A imagem do corpo funciona, muitas vezes, como um modo de sustentar o que está materializado no corpo da escrita desses sujeitos, dando visibilidade a um modo de se subjetivar que passa necessariamente pelo corpo. Um corpo que diz de si, mas que se mostra muito mais ao outro, que está sempre vigilante e vigiado ${ }^{4}$ por quem os espreita e os segue nos trilhos da rede virtual. "É dócil um corpo que pode ser submetido, que pode ser utilizado, que pode ser transformado e aperfeiçoado" (FOUCAULT, 1999, p. 118).

Dessa forma, para que possamos pensar a produção de subjetividades, é preciso considerar o movimento do sujei- to, que, já determinado por sua inscrição na ordem do significante da língua e do espaço virtual, inscreve-se nesse lugar tanto pela projeção da imagem do seu corpo quanto pela escrita. A produção de subjetividade, portanto, não está desvinculada nem da língua, nem da escrita, nem do corpo, constituindo-se na relação entre singularidade e alteridade.

A escrita representa, entre outras coisas, um modo de o sujeito singularizar-se; "é inscrição de si, que se dá, ao mesmo tempo, em dois sentidos: de fora para dentro e de dentro para fora" (ECKERT-HOFF; CORACINI, 2010, p. 9). Ou seja, ao escrever, o sujeito diz de si para o outro e o outro diz/determina a sua escrita. Portanto, os movimentos de subjetivação desse sujeito-escrevente sofrem não só determinações da inscrição do sujeito em si e no outro, mas também das condições socio-históricas e ideológicas em que esses sujeitos (o eu e o outro) estão inseridos. Por isso, a escrita é sempre cerceada pelos mecanismos de regulação social. Tomamos, pois, consoante a leitura de Gadet et al., "a subjetividade como efeito da interpelação de que o sujeito é o lugar, pelo viés da identificação" (2014, p. 64). Ou seja, não nos interessa pensar o sujeito na sua individualidade, mas como processo que resulta da relação do seu eu (individual) e do lugar social que ocupa, observando como esse lugar é projetado discursivamente, pelo viés da identificação.

Entendemos o sujeito na análise do discurso, seguindo Althusser, como uma categoria (noção) que é: 
[...] constitutiva de toda ideologia, mas, ao mesmo tempo, e imediatamente [...] não é constitutiva de toda ideologia, uma vez que toda ideologia tem por função (e é o que a define) 'constituir' individuos concretos em sujeitos (ALTHUSSER, 1985, p. 93, grifo do autor).

Eis o processo de interpelação a que todo indivíduo está submetido sem que se dê conta disso.

Paul Henry (1997, p. 30) frisa a aproximação da formulação da noção de sujeito de Pêcheux à de Althusser nessa interdependência entre a constituição do efeito ideológico no funcionamento da noção de sujeito e do funcionamento da própria ideologia nas práticas sociais. Portanto, sujeito e ideologia são noções indissociáveis para Pêcheux na análise do discurso. O sujeito é e será sempre "um indivíduo interpelado em sujeito" pela ideologia, em quem o inconsciente trabalha no funcionamento de uma série de ilusões próprias ao "teatro da consciência” (PÊCHEUX, [1975] 2014, p. 155). Neste trabalho, quando pensamos as narrativas de si observando os sujeitos-blogueiras, estendemos nossa visão a esses sujeitos afetados tanto pela linguagem quanto pelo inconsciente e pela ideologia.

Assim, o sujeito é constituído pelos esquecimentos, ${ }^{5}$ por meio dos quais ele tem a ilusão de ser a fonte do sentido e também do controle do seu dizer. Em Semântica e discurso, Pêcheux ([1975] 2014) defende que o lugar do sujeito não é vazio, sendo preenchido por aquilo que ele designa forma-sujeito, ou sujeito do saber de uma determinada formação discursiva ${ }^{6}$ Isso significa dizer que o sujeito do discurso, que jamais está livre da ideologia, funciona por meio de sua inscrição em uma ou outra formação discursiva, por sua vez ligada a uma formação ideológica. É “o processo da interpelação-identificação que produz o sujeito no lugar deixado vazio" (PÊCHEUX, [1975] 2014 , p. 145). Assim, ao escrever e narrar sobre si, o sujeito-blogueira escreve, mas, sobretudo, inscreve-se em dizeres ideologicamente determinados.

Pêcheux entende a ideologia e o inconsciente como estruturas-funcionamentos, por desempenharem, no discurso, o papel de "dissimular sua própria existência no interior mesmo do seu funcionamento, produzindo um tecido de evidências 'subjetivas" ([1975] 2014, p. 138-139, grifo do autor). Com isso, o teórico deixa claro que a categoria sujeito funciona como um efeito ideológico e inconsciente por meio do qual o indivíduo é interpelado pela ideologia, reconhecendo-se a si mesmo e estando submetido à ilusão de completo controle do seu dizer. Nesse jogo entre o assujeitamento e a ilusão de controle do dizer, o sujeito constitui-se autor pela escrita.

Coracini (2010) elenca alguns pressupostos para pensarmos a escrita em uma perspectiva discursiva que nos ajudam a refletir sobre o movimento de subjetivação do sujeito nessas narrativas de si. Segundo a autora, produzir um texto significa: a) "construir para si uma identidade, um lugar social, uma certa visibilidade, ainda que esta consista numa resposta a uma autoridade que 
detém o poder" (2010, p. 25); b) "um ato de escritura, ou melhor, de in-scrição numa superfície vazia (papel em branco ou tela vazia) - de si, em si e no outro" (2010, p. 29); c) "permitir-se explicitar as fantasias, os devaneios" (2010, p. 32). Esse último pressuposto a autora reserva para o que ela chama de texto criativo.

Entendemos, no entanto, que esses três movimentos marcam a produção de subjetividades nas narrativas de si nos blogs, já que os devaneios, as fantasias se presentificam nas publicações diárias dessas blogueiras (os posts), mesmo não estando necessariamente reservados à escrita criativa. Observamos que os processos de produção de sentidos que são dominantes nesses blogs são os processos parafrásticos, e não os polissêmicos. Segundo Orlandi:

[...] os processos parafrásticos são aqueles pelos quais em todo dizer há algo que se mantém, isto é, o dizível, a memória. A paráfrase representa assim o retorno aos mesmos espaços do dizer. Produzem-se diferentes formulações do mesmo dizer sedimentado. A paráfrase está do lado da estabilização. Ao passo que, na polissemia, o que temos é deslocamento, ruptura de processos de significação. Ela joga com o equívoco (2001, p. 36).

Então, se a polissemia é que produz deslocamento, a criatividade, como diz a autora, produz somente nos processos polissêmicos. Não é isso o que vemos funcionando nesses blogs no que diz respeito aos dizeres sobre o corpo feminino. Vejamos um exemplo que trata-se de uma publicação no aplicativo Instagram $^{7}$ de Niina Secrets, uma blogueira muito bem-sucedida no espaço virtual e no ramo de blogs de moda e beleza. A escolha por uma publicação em um aplicativo fora do blog oficial marca-se por um gesto analítico de compreensão, pois o efeito-autor, ${ }^{8}$ que confere unidade ao discurso de cada blogueira, não se dá via a unidade do canal de comunicação ou do suporte (como em um livro, um álbum, etc.).

Nessa dinâmica da blogagem de moda feminina, temos como elemento de unidade da autoria a própria imagem da blogueira (imagem do corpo); é essa imagem que confere identidade à escrita e às publicações da blogueira no espaço virtual, independente do aplicativo ou canal em que está. Isso justifica nossa opção metodológica de não distinguir publicações de blogs, do Instagram ou mesmo do YouTube, uma vez que todos esses canais servem como veículos das narrativas de si, cujo efeito-autor está funcionando na imagem de cada uma das blogueiras.

A publicação reproduzida na Figura 1 apresenta os diários de dieta de Niina Secrets, nos quais a blogueira materializa seus devaneios e fantasias não só nas fotos postadas, mas também no comentário. Ou seja, a sua fantasia, o seu desejo, é o corpo perfeito. E corpo perfeito é sinônimo de corpo magro. Um corpo que passa pela domesticação de que, para ser bonito, é preciso ser magro. Pura repetibilidade, retorno ao mesmo lugar de dizer e desse sentido cristalizado e estabilizado socialmente. Nada de polissemia nem de criatividade. 
Figura 1 - Antes e depois da dieta de Niina Secrets - Reprodução/Instagram

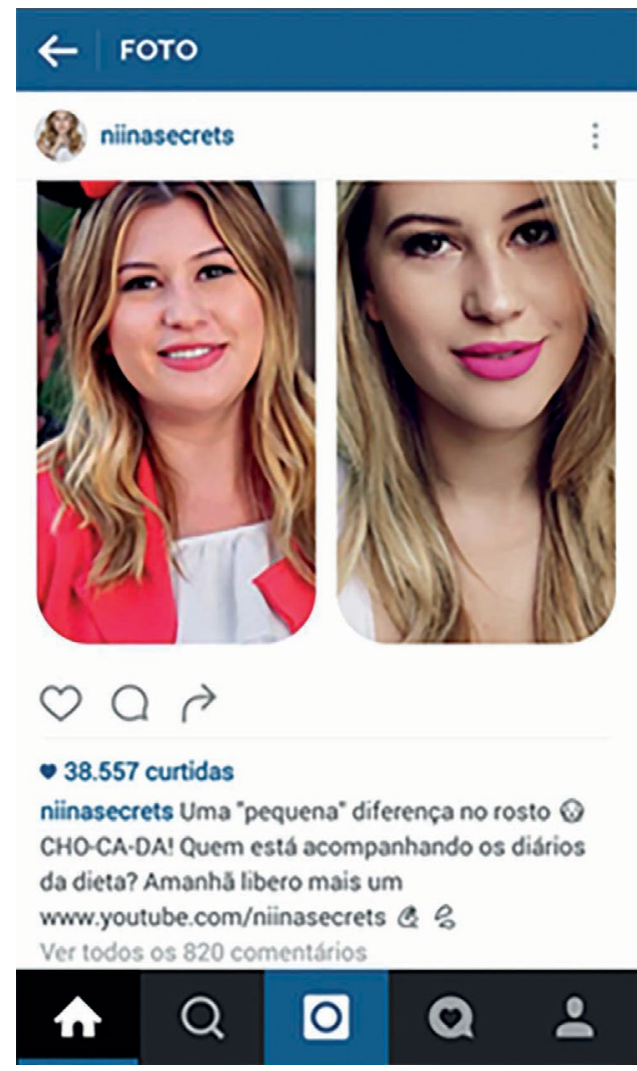

Fonte: Disponível em: <https://www.instagram.com/p/ BC1K1acS_OE/?taken-by=niinasecrets>. Acesso em: 25 mar. 2016.

Consideramos a imagem apresentada na Figura 1 um exemplo de materialidade dos blogs atuais, que nasceram como diários virtuais, em que seus autores registravam atividades cotidianas. Segundo Cortes, desde o seu surgimento, em 1990, até hoje,

[...] o blog foi se transmutando de um diário online intimista, embora paradoxalmente público, para uma espécie de diário coletivo, do qual emergem vozes e discursos (2015, p. 37).
Conforme, ainda, a autora, após 2002, com a popularização das redes de relacionamento, os blogs ganharam ainda mais espaço e ampliaram sua função, não mais agora sendo espaço apenas de relatos diários, mas funcionando como veículos de notícias, debates políticos, e, sobretudo, como espaço de divulgação comercial. O segmento editorial virtual de moda e beleza feminina, porém, identifica-se muito com os blogs do princípio, que se caracterizavam mais como diários do que como espaços de debate político, contudo, com o deslocamento de sua funcionalidade. O testemunho nos blogs, hoje, adquire uma finalidade comercial e está sustentado no consumo.

Nas narrativas que materializam imagem e língua, observamos o processo parafrástico no que estamos entendendo como o discurso disciplinador do corpo feminino - esse que vem estabelecer a magreza como padrão a ser obedecido. Assim como Bressan, atribuímos o alinhamento dessas blogueiras a esses padrões:

[...] à inserção do sujeito numa formação social capitalista e consumista, em que a cultura, em seus aspectos de singularização do sujeito, é apagada, sobrepondo-se o que podemos chamar de massificação global da cultura" (2015, p. 210, grifo nosso).

No texto verbal e nas imagens, observamos o registro virtual de uma narrativa de si que marca o tempo passado e o presente pela imagem e pela via do testemunho da transformação - a narrativa de uma história de sucesso. A mudança (positiva) exibida na tela é oferecida ao olhar do outro como registro de uma 
saga compartilhada diariamente por sua protagonista. A subjetividade, sempre atravessada pelo olhar do outro e sempre oferecida à sua apreciação nesse espaço da exposição de si, aparece marcada linguisticamente no paralelismo imagético que provoca uma relação de temporalidade (antes e depois). No texto verbal, a subjetividade verifica-se pelo modo como a blogueira destaca com aspas a palavra "pequena", apontando para o efeito de sentido contrário, isto é, sublinha a grande diferença entre seu antes e depois. Isso é reforçado, em seguida, quando flagramos o ponto máximo da sua subjetividade marcada no fio do discurso: CHO-CA-DA.

$\mathrm{Na}$ escrita, o registro de palavras inteiras com letras maiúsculas, com a pausa marcada pela divisão silábica, indica o efeito de sentido prosódico de grito. Tal materialização nos revela os desejos e os devaneios dessa narrativa de si. Ou seja, o sujeito permite-se explicitar suas fantasias e devaneios. Mais do que isso, trata-se de um movimento de inscrição desse sujeito em uma tela vazia. In-scrição de si, em si e no outro, como nos diz Coracini (2010). Uma inscrição que constrói para esse sujeito visibilidade social. Tudo isso atravessado pelo olhar do outro, que determina esses movimentos nos gestos de escritura de si. Portanto, os pressupostos de que nos fala Coracini (2010) sobre a escrita não ocorrem de forma estanque, mas enlaçam-se na experiência das narrativas de si que circulam nos blogs de moda feminina.

Segundo Rickes (2002), a escrita faz trabalhar a falta que é constitutiva do sujeito. Mas, "ao apagar a falta, o sujeito não faz outra coisa senão revelá-la, através de um gesto que é singular" (AGUSTINI; GRIGOLETTO, 2008, p. 146). Ou seja, a escrita, ao (re)velar a falta que constitui o sujeito, traz à tona traços da sua singularidade que colocam em xeque o efeito elementar de unicidade daquilo que se diz ao escrever, abrindo pontos de deriva no discurso. A deriva de sentidos que se produz a partir de um processo de clivagem entre aquele que escreve, aquilo que escreve e aquele que lê, que é o outro necessariamente implicado nesse processo.

A alteridade, tomada aqui sobretudo pelo viés materialista, mas também atravessada pelo psicanalítico, ${ }^{9}$ funciona, então, como uma forma tanto de determinar como de preencher essa falta do sujeito e a incompletude dos sentidos. Como nos diz Pêcheux:

[...] é porque há o outro próprio nas sociedades e na história, correspondente a esse outro próprio ao linguajeiro discursivo, que aí pode haver ligação, identificação ou transferência, isto é, existência de uma relação abrindo a possibilidade de interpretar (1997, p. 54).

O sujeito, então, a partir de movimentos subjetivos, identifica-se com esse outro (outro sujeito, outro sentido, etc.) que o determina. $\mathrm{E}$, nesses processos de identificação, escapa o desejo de um corpo que precisa ser exaltado (por meio das muitas curtidas), em um apelo estético via imagem e via docilidade. A sequência imagética do "antes e depois" está pautada em um regime de intensa repetibilidade no espaço virtual, e sempre do mesmo 
sentido para o outro: de gorda para magra; de pior para melhor. Observemos a seguir, na Figura 2, os comentários da postagem anteriormente reproduzida com algumas manifestações de leitoras (todas se inscrevem com registros digitais femininos) da blogueira Niina Secrets a respeito do seu "antes e depois":

Figura 2 - Comentários na imagem do "antes e depois" da dieta de Niina Secrets Reprodução/Instagram

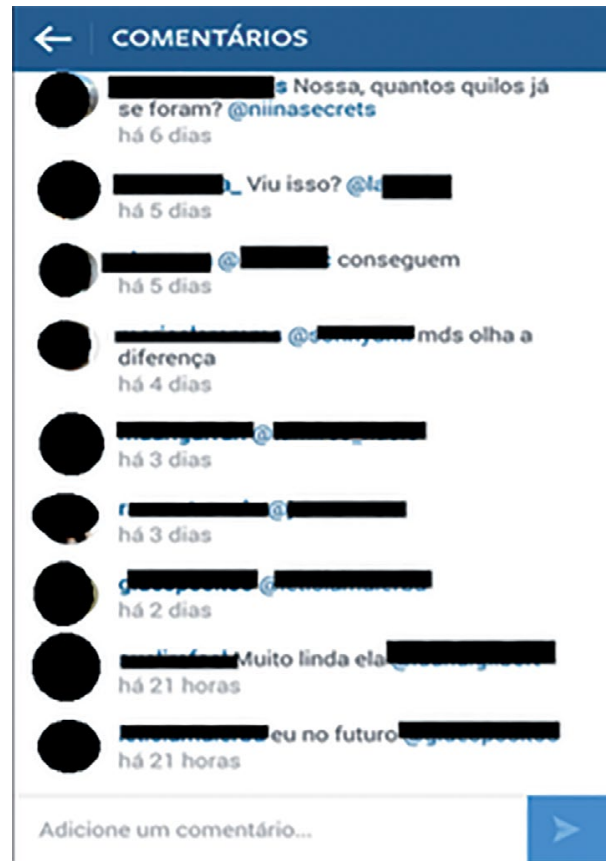

Fonte: Disponível em: <https://www.instagram.com/p/ BC1K1acS_OE/?taken-by=niinasecrets $>$. Acesso em: 25 mar. 2016.

Tais comentários reforçam o que dizíamos sobre a determinação do olhar do outro na narrativa de si, e revelam a identificação desses sujeitos com esse sentido cristalizado sobre a relação in- trínseca entre magreza e beleza. Revelam um desejo de ser igual a Niina, que aqui serve como um modelo de identificação para as suas seguidoras. Nos blogs de moda feminina, como um todo, observa-se uma intensa regularidade de dizeres e de signos imagéticos relacionados ao padrão estético feminino vigente, que preconiza a mulher magra, "bem vestida" e maquiada. A mulher que "se cuida" e, também, "cuida da alimentação", para assim ocupar o lugar social de mulher bonita e bem-sucedida.

A narrativa de si funciona, então, nos blogs, como um modo de submissão, mas também como um modo de exposição. Submissão às regras que regulam o lugar social que o sujeito-blogueira ocupa no momento da escrita e que permitem que ele seja reconhecido pelo outro, que tenha visibilidade social pelo modo como "alinha-se a uma certa ordem do discurso vigente, ao jogo de formações discursivas" (CORACINI, 2010, p. 27), que determinam o que pode e deve ser dito na prática discursiva, ou melhor, no discurso que está sendo produzido. E exposição de si, pois, mesmo submetendo-se a determinadas coerções sociais, ao escrever, o sujeito sempre busca se mostrar, deixa algo de si marcado em seu texto. É esse jogo entre exposição e submissão que vemos materializado na postagem ilustrada pela Figura 3, em que a blogueira Niina Secrets se apresenta. 
Figura 3 - Sobre Niina Secrets - descrição no blog oficial

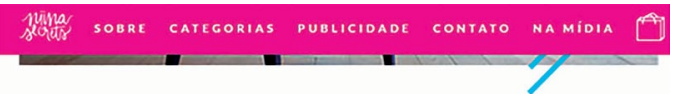

Quem é a Niina?

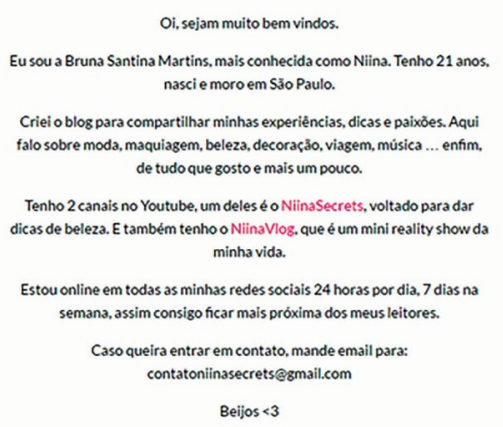

Fonte: Disponível em: <http://niinasecrets.com.br/ sobre/\#content>. Acesso em: 29 mar. 2016.

Na seção Sobre, o sujeito-blogueira apresenta-se ao público em uma narrativa que marca, ao mesmo tempo, a exposição de si, a submissão ao outro e a coerção social, que é própria do ser sujeito na rede. Tal coerção materializa-se pela necessidade, demonstrada na formulação do dizer de Niina, de estar o tempo todo disponível: "Estou online em todas as minhas redes sociais 24 horas por dia, 7 dias na semana, assim consigo ficar mais próxima dos meus leitores”. Essa fala, que é da ordem do impossível, do irrealizado, em relação aos efeitos de sentido, mas que é possível de ser formulada na língua, produz um efeito de completude no virtual no que tange à capacidade do dizer e do expor tudo sobre sua própria vida.

Pêcheux nos mostra que não é possível desvincular "o objeto face a qualquer discurso feito a seu respeito", já que há sempre, no interior do universo físico-humano desses objetos, "pontos de impossível, determinando aquilo que não pode ser 'assim"' (1997, p. 29). No caso dos blogs e, mais especificamente da seção que estamos analisando, o objeto é a própria vida da blogueira, exposta publicamente. Os pontos do impossível de se realizar, mais do que o impossível de se dizer, são observados na materialidade linguística do recorte destacado de sua fala. Em todos os momentos, em todos os dias, em todas as horas, a vida de Niina está exposta para a apreciação dos seus leitores, exposta ao olhar do outro. E isso se dá tanto pela escrita verbal quanto pela imagem, materializada em fotos e vídeos pelos diversos canais disponíveis no espaço virtual.

Essa exposição de si pode ser relacionada ao que Pêcheux (1997, p. 34) diz sobre as urgências da vida do sujeito pragmático, que respondem a uma "imperiosa necessidade de homogeneidade lógica", como se fosse possível tudo dizer, suprir esse desejo universal de "um mundo semanticamente normal", que passa, segundo o autor, pela relação de cada um com o seu próprio corpo. O desejo de ser normal que corresponde ao desejo de ser magro, ter o corpo perfeito.

Segundo Foucault (2004), escrever é "se mostrar", expor-se, fazer aparecer seu próprio rosto perto do outro, porque a escrita passa pelo corpo. Em nosso entendimento, os corpos das blogueiras também são parte de suas narrativas sobre si e expõem a relação de sua subjetividade 
com a alteridade - a saber, particularmente, no aspecto em que seus corpos dóceis, magros, estão em acordo com os padrões estéticos estabelecidos para que os corpos femininos sejam belos.

Por isso, concordamos com Gadet et al. a respeito de que:

[...] a subjetividade é o lugar de uma irredutível contradição, entre o sujeito como mestre de seus gestos, falas e pensamentos, e o sujeito como inscrição na linguagem na cadeia dos significante (2014, p. 62).

Contradição que constitui o sujeito, que é, ao mesmo tempo, interpelado ideologicamente e atravessado pelo inconsciente. Ou seja, no caso em análise, as blogueiras pensam ter o controle sobre o que dizem de si e das imagens dos seus corpos, não se dando conta de que sua subjetivação passa sempre pela determinação do outro, pelo discurso do capital que as assujeita. Esse movimento se explicita com relevância na sequência discursiva a seguir, retirada da Figura 3:

Criei o blog para compartilhar minhas experiências, dicas e paixões. Aqui falo sobre moda, maquiagem, beleza, decoração, viagem, música... enfim, de tudo que gosto e mais um pouco (grifo nosso).

Em uma relação de paralelismo semântico, o sujeito-blogueira põe em relação de equivalência produtos do mercado do consumo e suas experiências, dicas e paixões, que se resumem à moda, maquiagem, beleza, decoração, viagem, música - produtos da indústria da estética, do turismo e da cultura. Ou seja, o tudo que ela gosta, e "muito mais", está determinado pelo discurso do capital, e suas experiências passam, necessariamente, pelo consumo. Não à toa, esses elementos têm uma função comercial muito relevante no funcionamento dos blogs. Esses canais são patrocinados por empresas de cosméticos, de moda, de viagem, etc., e é dessa renda que vivem as blogueiras. Elas próprias, também, assinam produtos com seus nomes: tornam-se marcas. Suas experiências são seus produtos: seu meio de lucro e subsistência.

Esse assujeitamento ao discurso do capital, por sua vez, associa-se ao corpo magro e belo (um construto da indústria da moda e da beleza), e pode ser confirmado nas fotos das blogueiras de moda mais influentes e mais ricas da atualidade, que apresentamos na Figura 4, segundo um conjunto de sites, conforme o número de seguidores, alcance publicitário e poder de patrocínio.

Figura 4 - Imagens das blogueiras mais "poderosas" do Brasil

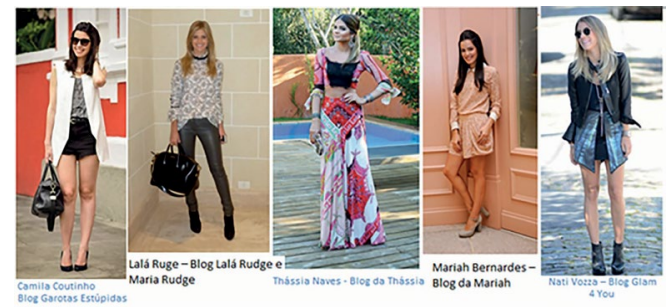

Fonte: Disponível em: <http://www.fashionbubbles.com/ destaque/saiba-quem-sao-as-blogueiras-de-moda-mais-poderosas-do-brasil-dicas-de-looks-e-o-segredo-do-sucesso/>. Acesso em: 23 fev. 2016.

Como se observa nas imagens retiradas das páginas das blogueiras, em uma relação parafrástica, todas elas exibem corpos magros, corpos como elementos sig- 
nificantes da escrita de si, adequados aos padrões da moda, ditados pelo discurso do capital, e ao imperativo de que "todo mundo sabe" que "é preciso ser magra para ser bonita". Observamos funcionando, nesse enunciado, o que Pêcheux denominou de pré-construído, o "sempre-já-aî" da interpelação ideológica. Ele "fornece-impõe a 'realidade' e seu 'sentido' sob a forma de universalidade" ([1975] 2014, p. 151).

É, pois, entre esse movimento de submissão e exposição que o sujeito se subjetiva. Contudo, a escrita, pela inscrição de seus corpos, também pode funcionar como um ato de resistência (CORACINI, 2010) a essa ordem social vigente, a esse imperativo. E, se há lugar para a resistência, é porque o movimento subjetivo não é homogêneo; é, ao contrário, como já pontuamos, lugar de irredutível contradição.

Nesse lugar contraditório, próprio da subjetividade, em um movimento tenso entre a identificação e a resistência, situa-se o discurso da blogueira Ju Romano, do blog Entre Topetes e Vinis (disponível em: <www.juromano.com. br $>$ ). Ao se adjetivar como "gorda", em sua descrição-narrativa de si, a blogueira subjetiva-se em uma posição marcada de alteridade em relação aos corpos e às imagens em rede parafrástica das blogueiras de moda. Analisamos, em seguida, um trecho de uma publicação em que esse movimento pode ser observado com mais profundidade. No Quadro 1, apresentamos um excerto da postagem "Confissões de uma mulher normal":
Quadro 1 - Reprodução de "Confissões de uma mulher normal", do blog Entre Topetes e Vinis

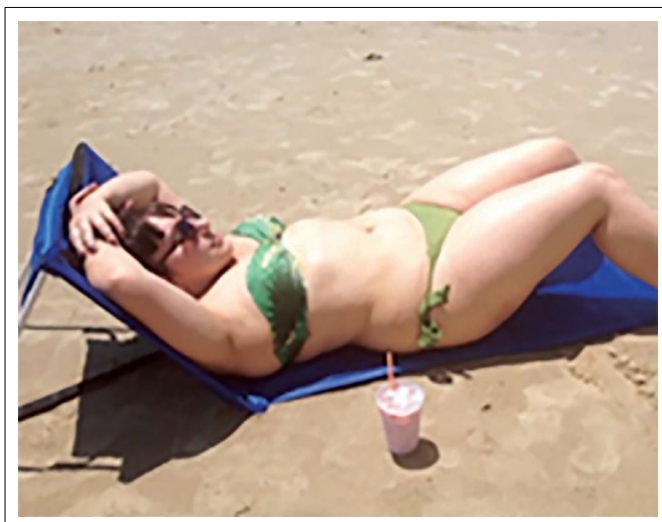

Hoje falo de boca cheia que sou uma gorda saudável e prefiro assim. Acho engraçado alguém falar "impossível alguém não querer emagrecer". Eu já fui magra e já fui gorda. Escolhi ser assim. Eu não quero emagrecer, estou assim por opção, obrigada. Eu nunca mais quis ser diferente do que eu sou. Sim, eu quero que amanhã eu sempre seja uma versão melhorada de hoje, mas que para isso eu não tenha que sacrificar as minhas horas de alegria e nem o meu prazer de viver. Que para isso, eu não tenha que derramar lágrimas toda vez que me vejo no espelho. Eu sou assim, gordinha, com a mente muito mais rápida que o metabolismo (grifo nosso).

Fonte: disponível em: <http://juromano.com/moda/confissoes-mulher-normal>. Acesso em: 23 fev. 2016.

A sequência apresentada é apenas um recorte de uma narrativa de si, que registra uma transformação interior/ exterior da blogueira. No entanto, desta vez, o antes e depois relata um movimento distinto do que observamos com a blogueira Niina Secrets. Ju Romano inicia seu relato com o enunciado "eu já fui obcecada por peso". Nele, marca-se 
linguisticamente no tempo passado a relação conflituosa do sujeito com seu corpo por meio do atributo peso, que é a medida dos corpos no padrão estético da magreza.

Na sequência discursiva com a imagem destacada, que trouxemos na Figura 5, considerando as materialidades linguística e fotográfica, o sujeito-blogueira de moda e beleza estabelece sua posição de resistência em relação ao discurso de que "para ser saudável, é preciso ser magra", de que "é impossível alguém não querer emagrecer" e que "não é possível que uma mulher seja gorda por opção" (o gênero feminino está presente no discurso pela marcação de gênero nas formas linguísticas da materialidade textual), afinal, como nos ensina Pêcheux, "não há ritual sem falhas; enfraquecimentos e brechas" ([1975] 2014, p. 277). A materialidade fotográfica arrebata esse posicionamento, pois, nos moldes do padrão estético em que a magreza é o ideal, ser gorda, usar biquíni e expor sua figura em uma publicação no espaço virtual significa um posicionamento de grande resistência; expor a si mesmo em um corpo gordo é "ousar se revoltar", "ousar pensar por si mesmo" ${ }^{10}$

No entanto, a formulação "sou uma gorda saudável" deixa escapar um não dito, um ato falho que se materializa no fio do discurso, atualizando um dizer próprio dos saberes do discurso da estética sobre o corpo feminino: as gordas não são saudáveis. O artigo indefinido "uma (gorda)" faz com que, contrariando o discurso do capital, a formulação também o afirme: as gordas não são saudáveis; eu, porém, sou uma gorda saudável. Inscreve-se no interior do discurso uma alteridade via identificação fora da ordem do controle, mas que, pela necessidade de fugir dos padrões estéticos de beleza, acaba fazendo emergir outro desejo: o do corpo saudável. Desejo esse que se manifesta no corpo da escrita, já que:

[...] no exercício da escrita, a alteridade se impõe, inconscientemente, à linearidade discursiva instituída. No entanto, é só por essa imposição que a singularidade emerge, já que a subjetividade encontra morada, justamente, no intervalo, no movimento entre singularidade e alteridade (SCHONS; GRIGOLETTO, 2009, p. 601).

Como afirmam Agustini e Grigoletto, ocorre, nesse tipo de formulação, "a abertura flagrante da enunciação ao real da língua, ou a 'alíngua', irreversivelmente designada, ao mesmo tempo em que é barrada" (2008, p. 147), pois esse é o espaço do impossível, daquilo que não é possível dizer na linearidade intradiscursiva, mas que significa.

Essa sequência evidencia, ainda, a dor e o sofrimento causados pela não adequação aos padrões físicos ditados pelo discurso da estética sobre o corpo feminino, negando a posição do sujeito que se submete aos sacrifícios necessários para estar no lugar da mulher magra:

Sim, eu quero que amanhã eu sempre seja uma versão melhorada de hoje, eu não tenha que sacrificar as minhas horas de alegria e nem o meu prazer de viver. Que para isso, eu não tenha que derramar lágrimas toda vez que me vejo no espelho. 
Observamos nesse trecho o aspecto confessional do testemunho que irrompe a memória das narrativas de si, remetendo-as aos diários pessoais. Revelam-se confissões de si em confronto com o outro; são dilemas pessoais travados pela alteridade veiculados em um espaço virtual usado para influenciar, mas também para se revelar.

Revelar, revelar-se, de um lado, é encontrar, é encontrar-se. Por sua vez, nesse encontro, capturamos, capturamo-nos. Mas capturamos instantes indefinidos de compreensão de cada ato de escritura (SCHERER, 2010, p. 108).

Por fim, em relação às formulações dessa narrativa que trouxemos, gostaríamos de destacar a presença significativa da palavra "normal" no título do texto. Ao se confessar "uma mulher normal" e desenvolver uma narrativa em que se posiciona como resistente ao discurso de que "é preciso ser magra para ser saudável" e de que "é preciso ser magra para ser bonita" (inscrevendo-se no espaço virtual como blogueira de moda e de beleza sendo uma gorda), o sujeito-blogueira busca deslocar esses sentidos cristalizados socialmente, colocando em outro lugar a questão da normalidade. Ser normal não é buscar o ideal do corpo imposto socialmente, mas viver sem se submeter a essa padronização estética.

No entanto, ao longo do seu relato da experiência de si, ela também confessa que já buscou essa outra normalidade, que já sofreu e odiou seu próprio corpo, nessa busca incessante pela "imperiosa necessidade de homogeneidade lógica” que aponta para um único padrão de beleza aceitável socialmente. Se, na narrativa de si de Niina Secrets, a subjetivação da blogueira passa pelo desejo do corpo magro, perfeito, em Ju Romano, a subjetivação é marcada pelo desejo de aceitar a si própria, com seu corpo gordo e sem fazer dietas. Interessante notar, porém, que, em ambos os casos, a normalidade passa pela aceitabilidade do outro. Ou seja, nessas narrativas de si, o que o sujeito-blogueira busca, em última instância, é a identificação com o outro, ou porque as blogueiras funcionam como modelo de identificação para o outro, ou porque buscam no outro essa identificação.

Esse outro não é apenas o seu seguidor, o seu leitor. Trata-se do outro discursivo, a exterioridade, o jogo complexo de dizeres que atravessam todo e qualquer discurso, que é exterior a si mesmo. Portanto, esse outro, no caso dos discursos dos blogs de moda feminina, pode ser tanto o discurso da saúde, quanto o discurso da estética, do consumo e, até, inclusive, os discursos de resistência, que têm se alastrado no espaço virtual devido ao seu funcionamento.

\section{A experiência de si pelas narrativas: histórias inacabadas...}

Observamos, nos blogs analisados, como as narrativas de si materializam experiências cotidianas das blogueiras que passam pelo adestramento do olhar do outro, seja para se assujeitar aos 
padrões estéticos impostos socialmente, seja para resistir a eles. Em ambos os casos, no entanto, o corpo precisa estar exposto, inscrevendo-se, junto com a escrita, nessas narrativas. Exposição da imagem do corpo perfeito, esbelto, magro, que serve como modelo de identificação para o outro que deseja se inscrever na rede do sentido dominante, determinado pelo discurso do capital de que "mulher bonita é mulher magra". Ou exposição da imagem do corpo gordo, de biquíni, que precisa ser exposto para reafirmar o que aparece no corpo da escrita de si e, também, para dizer, que é preciso coragem, "ousar se revoltar", para resistir a esse sentido dominante. Um corpo, ainda assim, que também serve como modelo de identificação àquelas mulheres que não se inscrevem na rede do sentido dominante, e que são designadas pela blogueira de "normais".

Assim, no intervalo entre normalidade e anormalidade, entre o assujeitamento e a exposição, entre a singularidade e a alteridade, o sujeito-blogueira, constitutivamente dividido, subjetiva-se, deixando traços, marcas de histórias que nunca acabam de se es(ins)crever, que são narradas cotidianamente pelas blogueiras a partir das experiências que vivenciam com os produtos que divulgam e consomem. Experiências que são compartilhadas com o outro - a seguidora, o discurso da estética, do consumo, etc. -, que, ao mesmo tempo, preenche a falta, o desejo, mas também determina, domestica os movimentos desse sujeito nas narrativas de si.
E, em nosso desejo de realizar um efeito de fechamento para esta análise-descrição-interpretação, que não cessa de se atualizar na frenética ordem do discurso digital, do qual já não temos mais como medir início, meio e fim, fica a certeza da relação entre os sujeitos e os discursos, entre os sujeitos e os sujeitos e entre os analistas e os discursos: uma relação de nunca acabar. Ao iniciar este texto, que busca analisar narrativas de si pelo viés do testemunho e da alteridade por meio da imagem e da materialidade do corpo presente no virtual, realizamos um gesto testemunhal que registra uma relação de nunca acabar com alguém que já não está mais presente, em corpo materializado. Um alguém que ficou inscrito em todos nós, no discurso, em nossas subjetividades-alteridades...

Por isso, é muito difícil colocar um ponto final neste texto, que tem como objetivo, entre outros, prestar uma homenagem a esse alguém que já se foi - muito jovem ainda - e deixou muitas histórias inacabadas, muitos projetos de vida sem concluir, muitos desejos que pulsam em suas telas e seus escritos. Daí as reticências. As reticências que remetem a um silêncio que não pode ser preenchido com palavras, mas que permanece aí significando, reverberando os sentidos da sua existência entre nós, Carme. Então, no lugar do ponto final, que sempre se produz como efeito de fechamento, preferimos deixar aos nossos leitores - os outros implicados nesse nosso gesto de escrit(ur)a - uma outra 
materialidade dessas narrativas, uma materialidade também produzida por Carme, para que cada leitor produza o seu próprio efeito de fechamento.

\section{Figura 5 - Vestido}

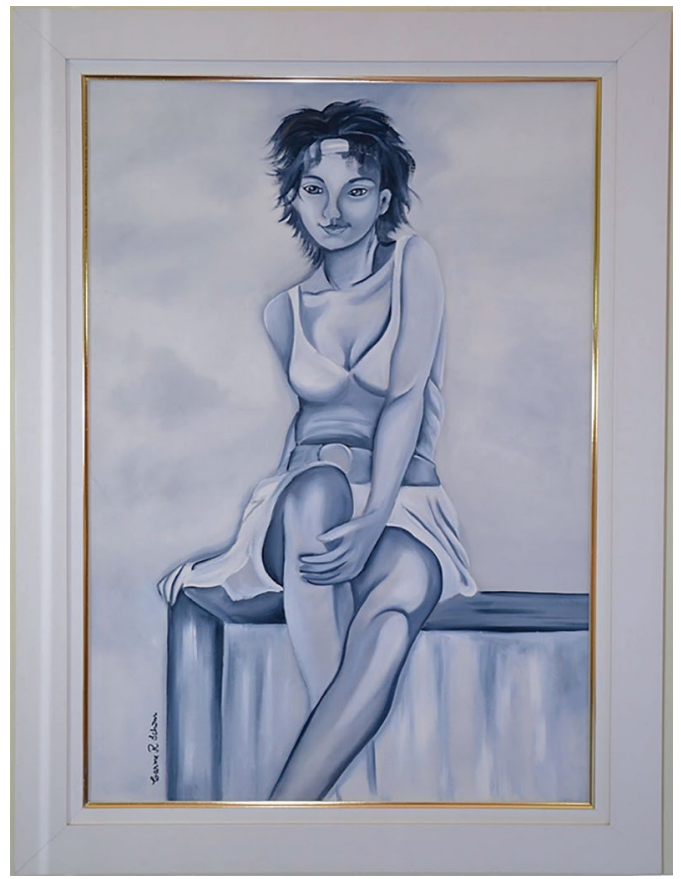

Fonte: tela de Carme Regina Schons.

\section{Le récit de soi dans les blogs de mode féminine: entre la subjectivité et l'altérité}

\section{Résumé}

Dans cette article, nous analysons la relation entre subjectivité et altérité, dans une perspective discursive, à travers des les récits de soi de blogs de mode féminine. Nous concevons le récit virtuelle de soi comme des mouvements du sujet caractérisés par l'expérience de l'écriture comme témoignage de soi et de l'autre. De plus, cette expérience est toujours associée à la matérialité de l'image du corps. Dans ce cadre, les analyses montrent que le mouvement de subjectivation des blogueuses est déterminé par l'altérité et se matérialise tant par l'écriture que par l'image du corps. Dans cet espace virtuel, le rapport de l'expérience s'inscrit discursivement par la présence de témoins, qui rendent possible des mouvements d'identification et de résistance déterminés par le discours du capital.

Mots-clés: Récit de soi. Blogs de mode féminine. Subjectivité. Altérité.

\section{Notas}

1 Essas palavras foram recortadas de e-mails que troquei com os filhos da Carme, por ocasião desta homenagem que preparávamos a ela.

2 Estamos entendendo aqui o espaço virtual como um espaço intervalar, de entremeio entre os espaços empírico e discursivo. Conforme Grigoletto, o espaço virtual "se caracteriza pelo entrelaçamento das práticas sociais e discursivas, [...] formando uma teia discursiva não-linear, saturada de links, nós, lacunas que supostamente possibilitam a deriva de sentidos para qualquer direção. Supostamente porque, embora links, imagens e outras materialidades presentes nas discursividades que circulam na rede, apontem sim para a deriva de sentidos, para outras possibilidades de leituras, os percursos de leitura e, por sua vez, dos sentidos são direcionados, controlados" (2011, p. 53). E esse controle, no caso dos blogs que estamos analisando, está materializado pelo atravessamento do discurso do capital, já que o que sustenta e mantêm ativos esses ambientes são os produtos divulgados e anunciados às suas seguidoras.

3 Disponível em: $<\mathrm{http}: / / w w w . g a r o t a s e s t u p i d a s$. com/>. Descrição do perfil de Camila Coutinho: "Sou recifense, tenho 26 anos e fico super feliz de ver que um projeto que começou como um hobby tenha tomado a proporção que o GE tem hoje! Temos atualmente uma média de 6 milhões de pageviews/mês e estamos em quinto no 
ranking dos 99 blogs de moda mais influentes do mundo, de acordo com o signature9.com! Por aqui, vocês vão encontrar muita moda, beleza, fofoquinhas, dicas de viagem e muito mais. Fiquem ligadas e sintam-se a vontade pra opinar tá?". Disponível em: <http://www. garotasestupidas.com/sobre-camila-coutinho/>. Acesso em: 23 fev. 2016.

4 O conceito de docilidade atualizado aqui foi evocado da reflexão de Michel Foucault (1999) em Vigiar e punir a respeito do controle do corpo nos séculos XVII e XVIII, na recém-sociedade industrial. Com os devidos deslocamentos históricos e culturais para a atual sociedade de consumo, pensamos que o conceito de docilidade do corpo cunhado pelo filósofo adequa-se ao movimento de "adestramento" estético dos corpos visualizados nas narrativas de si pelas escrituras nos blogs analisados.

5 Pêcheux e Fuchs (1997) afirmam que o sujeito é constituído por dois esquecimentos. O esquecimento número um, da ordem do inconsciente, faz com que todo o sujeito tenha a ilusão de que ele é a origem do sentido. Já, o esquecimento número dois, da ordem do consciente, pré-consciente, faz com que todo o sujeito tenha a ilusão do controle dos sentidos. São esses esquecimentos que produzem as duas evidências de que Pêcheux (2014) nos fala: a evidência do sujeito e do sentido.

6 Haroche, Pêcheux e Henry definem formação discursiva como "o que pode e deve ser dito (articulado sob a forma de uma harenga [sic], um sermão, um panfleto, uma exposição, um programa etc.) a partir de uma posição dada numa conjuntura dada [...]" (2007, p. 26).

7 Reiteramos o funcionamento eletrônico capilar dos blogs no espaço virtual. Eles espalham-se e estendem-se para outros aplicativos, de modo que consideraremos como corpus de análise todas as publicações associadas às blogueiras, ainda que não hospedadas no endereço do sítio oficial, como parte do discurso de seus blogs no espaço virtual.

8 Entendemos, na perspectiva da análise do discurso, que o efeito-autor é o que produz o efeito de unidade, coerência, legibilidade e dá legitimidade ao texto.

9 Sem entrarmos numa discussão psicanalítica sobre a noção de Outro em Lacan, reconhecemos que ele é o que estrutura o inconsciente do sujeito. Para os efeitos desse trabalho, vamos entender a alteridade a partir do que Pêcheux (2014) propõe sobre a relação entre inconsciente e ideologia, tomando-as como estruturas-funcionamento que produzem um tecido de evidências subjetivas para o sujeito. Reconhecemos, com Pêcheux, que o discurso é exterior a si mesmo, o que marca a heterogeneidade de todo e qualquer discurso que não se produz senão na relação com o outro. $O$ sujeito é dividido, assujeitado ao outro, determinado por aquilo que é da ordem do interdiscurso, mas é alienado dessa sua condição, graças ao esquecimento número um, que é da ordem do inconsciente. Conforme Authier-Revuz na afirmação de que, "constitutivamente, no sujeito e no seu discurso está o Outro, reencontram-se as concepções do discurso, da ideologia, e do inconsciente" (1990, p. 29, grifo da autora).

10 Pêcheux, no Anexo III de Semântica e discurso, assim termina seu texto falando de resistência: "[...] - não há dominação sem resistência: primado prática da luta de classes, que significa que é preciso 'ousar se revoltar' - ninguém pode pensar do lugar de quem quer que seja: primado prático do inconsciente, que significa que é preciso suportar o que venha a ser pensado, isto é, é preciso 'ousar pensar por si mesmo"' (2014, p. 281).

\section{Referências}

AGUSTINI, C. L. H.; GRIGOLETTO, E. Escrita, alteridade e autoria em análise do discurso. Matraga, Rio de Janeiro, v. 15, n. 22, p. 145-156, 2008.

AUTHIER-REVUZ, J. Heterogeneidade(s) enunciativa(s). Caderno de Estudos Linguísticos, Campinas, n. 19, p. 25-42, 1990.

ALTHUSSER, L. Aparelhos ideológicos de Estado: notas sobre os aparelhos ideológicos de Estado. Rio de Janeiro: Graal, 1985.

BRESSAN, M. Z. Sujeito, corpo e cultura: uma escuta discursiva sobre a anorexia nervosa. In: LEANDRO FERREIRA, M. C. (Org.). Oficinas de análise do discurso: conceitos em movimento. Campinas: Pontes, 2015. p. 195-220.

CORACINI, M. J. F. R. Discurso e escrit(ur)a: entre a necessidade e a (im)possibilidade de ensinar. In: ECKERT-HOFF, B.; CORACINI, M. J. R. F. (Org.). Escrit(ur)a de si e alteridade 
no espaço papel-tela: alfabetização, formação de professores, línguas materna e estrangeira. São Paulo: Mercado das Letras, 2010. p. 17-50.

CORTES, G. R. Do lugar discursivo ao efeito-leitor: a movimentação do sujeito no discurso em blogs de divulgação científica. 2015. 268 f. Tese (Doutorado em Linguística) - Universidade Federal de Pernambuco, Recife, 2015.

ECKERT-HOFF, B.; CORACINI, M. J. R. F. (Org.). Escrit(ur)a de si e alteridade no espaço papel-tela: alfabetização, formação de professores, línguas materna e estrangeira. São Paulo: Mercado das Letras, 2010.

FOUCAULT, Michel. Vigiar e punir: nascimento da prisão. 20. ed. Petrópolis: Vozes, 1999.

A escrita de si. In: FOUCAULT, Michel. Ética, sexualidade, política. Trad. Elisa Monteiro e Inês Autran Dourado. Rio de Janeiro: Forense Universitária, 2004. (Organização e seleção de textos de Manoel Barro da Motta). p. 144-162.

GADET, F. et al. Nota sobre a questão da linguagem e do simbólico em psicologia. In: PÊCHEUX, M. Análise de discurso: Michel Pêcheux. Campinas: Pontes, 2014. Seleção de textos de Eni Orlandi. p. 55-71.

GRIGOLETTO, E. O discurso nos ambientes virtuais de aprendizagem: entre a interação e a interlocução. In: GRIGOLETTO, E.; DE NARDI, F. S.; SCHONS, C. R. (Org.). Discurso em rede: práticas de (re)produção, movimentos de resistência e constituição de subjetividades no ciberespaço. Recife: UFPE, 2011. p. 47-78.

HAROCHE, C.; PÊCHEUX, M.; HENRY, P. A semântica e o corte saussuriano: língua, linguagem, discurso. In: BARONAS, R. L. (Org.). Análise do discurso: apontamentos para uma história da noção-conceito de formação discursiva. São Carlos: Pedro \& João, 2007. p. 13-31.

HENRY, P. Os fundamentos teóricos da 'análise automática do discurso' de Michel Pêcheux (1969). In: GADET, F.; HAK, T. (Org.). Por uma análise automática do discurso: uma introdução à obra de Michel Pêcheux. 3. ed. Campinas: Unicamp, 1997. p. 13-38.

ORLANDI, E. P. Análise de discurso: princípios e procedimentos. 3. ed. Campinas: Pontes, 2001.

À flor da pele: indivíduo e sociedade. In: MARIANI, B. (Org.). A escrita e os escritos: reflexões em análise do discurso e psicanálise. São Carlos: Claraluz, 2006. p. 21-30.

PÊCHEUX, M. Semântica e discurso: uma crítica à afirmação do óbvio. 5. ed. Campinas: Unicamp, 2014. (Originalmente publicado em 1975).

O discurso: estrutura ou acontecimento. 2. ed. Campinas: Pontes, 1997.

PÊCHEUX, M.; FUCHS, C. A propósito da análise automática do discurso: atualizações e perspectivas. In: GADET, F.; HAK, T. (Org.). Por uma análise automática do discurso: uma introdução à obra de Michel Pêcheux. 3. ed. Campinas: Unicamp, 1997. p. 163-252. (Originalmente publicado em 1975).

RICKES, S. M. A escritura como cicatriz. Educação \& Realidade, Porto Alegre, n. 27, p. 51-71, jan./jun. 2002.

SCHERER, A. E. A escrit(ur)a de si: uma história do sujeito pela alteridade. In: ECKERT-HOFF, B.; CORACINI, M. J. R. F. (Org.). Escrit(ur)a de si e alteridade no espaço papel-tela: alfabetização, formação de professores, línguas materna e estrangeira. São Paulo: Mercado das Letras, 2010. p. 107-119.

SCHONS, C. R.; GRIGOLETTO, E. Escrita e subjetividade na velhice: traços constitutivos de memória e identidade pelo testemunho em narrativas. In: CONGRESSO INTERNACIONAL DA ABRALIN, 6, 2009, João Pessoa. Anais... João Pessoa: Idéia, 2009. p. 597-603. Organização de D. HORA. 1 CD-ROM. 